Economic Model Building 


\section{ECONOMIC MODEL BUILDING}

F. Neal

Lecturer in Economic and Social Statistics at the University of Salford

and

R. Shone

Esmée Fairbairn Research Fellow at the University of Sheffield 
(c) F. Neal and R. Shone 1976

Softcover reprint of the hardcover 1st edition 1976

All rights reserved. No part of this publication may be reproduced or transmitted, in any form or by any means, without permission.

\author{
First published 1976 by \\ THE MACMILLAN PRESS LTD \\ London and Basingstoke \\ Associated companies in New York Dublin \\ Melbourne Johannesburg and Madras
}

SBN 333191374 (hard cover)

333191382 (paper cover)

ISBN 978-0-333-19138-5 ISBN 978-1-349-15673-3 (eBook)
DOI 10.1007/978-1-349-15673-3

Typeset in Great Britain by

Reproduction Drawings Ltd

This book is sold subject to the standard conditions of the Net Book Agreement.

The paperback edition of this book is sold subject to the condition that it shall not, by way of trade or otherwise, be lent, re-sold, hired out, or otherwise circulated without the publisher's prior consent in any form of binding or cover other than that in which it is published and without a similar condition including this condition being imposed on the subsequent purchaser. 


\section{Contents}

Preface and Acknowledgements $\quad$ ix

Introduction $\quad \mathrm{xi}$

1 THE STRUCTURE OF SCIENTIFIC EXPLANATION

1.1 What is Science? 1

1.2 Scientific Explanation 2

1.3 Truth and Logic 4

1.4 Scientific Laws 6

(a) Causal laws $\quad 7$

(b) The hierarchy of laws 8

(c) Laws and empirical generalisations 9

(d) Laws and nomic necessity 11

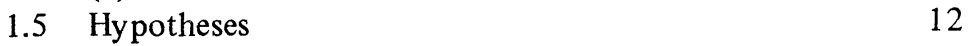

$\begin{array}{lll}1.6 & \text { Theories } & 16\end{array}$

1.7 Models: A First Analysis 17

1.8 Probabilistic Laws and Hypotheses 20

1.9 Where Do We Go From Here? 24

2 RELATIONSHIPS BETWEEN ECONOMIC VARIABLES

2.1 Problems in Defining Variables 27

2.2 Causation in Economic Relationships 33

2.3 Equations and Parameters 39

2.4 Types of Equations in Economic Relationships 44

(a) Behavioural equations 44

(b) Institutional equations 46

(c) Technical equations 47

2.5 Equations, Identities and Equilibrium 48 
3 DIMENSIONAL ANALYSIS IN ECONOMICS

3.1 Introduction 54

3.2 The Problem Stated 55

3.3 Ordinary and Physical Algebra 57

3.4 A More Formal Treatment of Dimensions 60

3.5 Primary Units in Economic Analysis 66

3.6 Dimensional Analysis as an aid to Checking Equations 69

3.7 Some Dimensional Aspects of Utility Theory 73

3.8 Summary and Conclusion $\quad 78$

4 SOME PRINCIPLES OF MODEL CONSTRUCTION
4.1 Introduction
80
4.2 What is a Model? An Informal Statement
81
4.3 What do we mean by 'An Economic Structure'?
83
4.4 Structural and Reduced Form Equations
88
4.5 Model Specification and Comparative Statics
91
4.6 An Illustration
93
4.7 Equilibrium and Meaningful Solutions
96
4.8 Conclusion
100
Appendix: The Application of Matrices to Linear
101
Economic Models

5 DYNAMIC ECONOMIC MODELS
5.1 Dynamics, the Next Step after Comparative Statics
103
5.2 The Cobweb Model
104
5.3 Static and Dynamic Multipliers
110
5.4 Discrete or Continuous Dynamic Models?
114
5.5 Some Useful Schemas and Diagrams
(a) Causal links in dynamic models
117
(b) Phase diagrams
119
5.6 The End of the Beginning

6 ECONOMIC POLICY MODELS

6.1 Why Policy Models? 125

6.2 Two Simple Policy Models 126

6.3 Interdependent Targets 131 
6.4 Consistency in Economic Policy Models 136

6.5 The Welfare Function of a Policy Model 136

$\begin{array}{lll}6.6 & \text { Stabilisation Policy } & 138\end{array}$

6.7 Monetary and Fiscal Policy 141

$\begin{array}{ll}6.8 \text { Conclusion } & 143\end{array}$

7 FROM THEORY TO PRACTICE

$\begin{array}{lll}7.1 & \text { Introduction } & 144\end{array}$

7.2 Stochastic Hypotheses 146

$\begin{array}{lll}7.3 \text { Stochastic Models } & 149\end{array}$

7.4 Ordinary Least Squares - Bivariate Regression 151

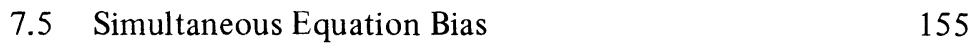

7.6 Non-Observable Variables: Expectations Hypothesis 157

7.7 Functional Form and the Concept of Linearity 160

$\begin{array}{lll}7.8 & \text { Estimation of Models } & 164\end{array}$

7.9 A Final Warning: Quality of Data 165

$\begin{array}{lr}\text { Postscript } & 166\end{array}$

$\begin{array}{lr}\text { Further Reading } & 168\end{array}$

$\begin{array}{ll}\text { Index } & 169\end{array}$ 


\section{Preface and Acknowledgements}

Most students at the end of their courses on economics can, with varying success, manipulate economic models by putting curves or equations through their paces and identifying equilibrium solutions. Unfortunately, this too often degenerates into a mechanistic operation. A major aim of this book is to illustrate the creativity involved in model construction and to develop in students the confidence to formulate their own models rather than have to rely on existing models in textbooks.

We believe that many issues that have been reserved for postgraduate programmes in economics have been sufficiently digested to be presented (albeit simply) in an undergraduate programme. This book is therefore intended for students of economics in their second and third years, and also as background reading for postgraduates.

Although no courses on 'model building' as yet exist, almost all courses in economics use the concept of a model. Rarely is the student made aware of the methodology lying behind model construction, and so this book, we hope, goes some way in filling this gap.

We would like to thank those friends and colleagues from Salford and Sheffield who have read and criticised some parts of the various drafts. Special thanks are due to Professor Fritis de Jong of Groningen University for his most valuable comments on an earlier version of Chapter 3. Although no references are given there, is an obvious debt to the literature but particularly to C. Christ, who, in his Econometric Models and Methods, first awakened our interest in this area. Also we would like to acknowledge the debt we owe to Ed Feige of the University of Wisconsin who convinced us both that economics is an intellectually stimulating subject. As usual, however, we alone are responsible for all errors and omissions. 


\section{Introduction}

For better or worse, economics since the 1950 s has been increasingly dominated by the methods of positive economics bringing with it the distinction between 'positive' economics and 'normative' economics. The essential distinction in the positivist approach to economics is that between statements of fact (even though they may be false) and statements of opinion. Additionally, positive economics requires that hypotheses be formulated in such a manner that they yield testable implications. The hypothesis so formulated can be subjected to tests which aim at its falsification. If such a hypothesis withstands rigorous tests then this is taken as evidence to support it. On the other hand, questions concerning what ought to be are not within the purview of the positive economist. For example, the statement that income ought to be redistributed in favour of the poor (or rich) is not suitable subject-matter for the methods of positive economics. How could one test such a hypothesis?

Accompanying this methodological approach to economics has been a simultaneous upsurge in the degree of sophistication in measuring economic variables and the techniques for testing hypotheses. In turn, these developments have made it necessary for teachers and students alike to achieve some minimal level of competence in mathematics and statistics. However, it is important to distinguish between method and techniques. The scientific method is not a method that gives us rules of discovery or mechanical procedures guaranteed to lead to increased understanding. Rather, it is the agreed rules concerning what the scientific community will accept as validation of hypotheses or claims to knowledge. Let us take a deliberately simplified instance. If a 
hypothesis is formulated thus, 'the sole cause of price inflation is increases in the money supply', certain testable implications would follow. The term 'scientific method' refers to the rules and procedures we adopt in judging the evidence that is produced to support hypotheses or theories. Now it is fairly clear that the techniques of the physical sciences are not, in general, available to the economist.

However, it is argued by many positivist economists that there is a unity of method between the social sciences and the physical sciences, namely that the formulation of hypotheses, the testing of their implications and the development of agreed procedures for falsifying hypotheses, are common to all branches of science. Such a view is not acceptable to many social scientists, including many economists. However, the fact remains that the majority of undergraduate students of economics spend a large part of their time studying models and theories at a fairly high level of abstraction. Explicitly or implicitly they absorb the attitudes of positive economics and pick up the language of 'scientism', that is laws, hypotheses, theories, models, testing, explanation, predictions, and so forth.

Such students, when they ask questions concerning the scientific standing of their subject, are often referred to the methods of the physical sciences as the model, par excellence, of the scientific method. This is understandable, given the positivists' position, but quite often the student has little or no understanding of either the methods or logic of discovery in the physical sciences. Our aim is not to defend positive economics against the radical economists but, given the importance placed on models in positive economics and the implicit methodology of their approach, it seemed useful to attempt, in Chapter 1, a brief introduction to explana ion in the physical sciences. This, we hope, will help students to assess themselves the claims concerning the unity of method claimed between economics and the physical sciences. We also believe that an understanding of the physical model of explanation will help them to see the relevance or irrelevance of the methods of positive economics.

The physical model of explanation is, for many social scientists, a narrow view of scientific explanation. After all, we would like to explain such events as the Second World War, the collapse of the old European empires, football violence, and so on. But any such attempt would have to call on a much wider variety of explanatory frameworks. We have concentrated on the physical model of explanation because its methods and logic seem to be the inspiration of much of positive 
economics and so is relevant to a book on model building. Of course, ideology and subjective values are not a part of the methods of the physical sciences and this raises the issue of whether positive economics is value free. Often this issue arises in connection with the role of assumptions in economic analysis. Positive economists would argue that the statements concerning oughts are not within the realm of scientific analysis. Hence, they are only concerned with what is, not with what ought to be. Some critics, mistakenly, argue that the assumptions of conventional economic analysis are value judgements. For example, if an analyst says 'Let us assume perfect competition', he is using a short-hand term for a number of assumptions. Nothing follows from assumptions as such. It is only when we introduce hypotheses that analysis can begin. Assumptions limit the domain of discussion. In the case of perfect competition, given hypotheses about profit-maximising firms, the law of variable proportions, and so on, we can analyse the equilibrium conditions of the firm and the industry Assumptions are value free. However, what is a value judgement is the choice of that particular type of analysis. The positivists' preoccupation with the analysis of resource allocation in a capitalist system is a value judgement. Assumptions are not; they are simply the conditions within which we analyse the implications of our hypotheses and theories.

It is often said that chapters on methodology are independent of the remainder of the book in which they appear. Such a claim can be made here, but this totally misses the point of methodology. The line of thought taken by the authors in discussing economic models is set out in Chapter 1. The fact that little reference is made back to this chapter does not mean that it is irrelevant to the remainder of the work. The criticisms that can be levelled against the chapters on model building are more likely as not to be concerned with differences in methodology.

Throughout courses on economics (and other related subjects) the student will be given the model of demand, the income-determination model, the $I S-L M$ model, the Harrod-Domar growth model, and so on. Everything suddenly appears in model form and yet what exactly constitutes a 'model' is never given. If something is to mean anything then it must have a restriction on interpretation. The term 'model' is becoming used in too wide a context and so means all things to all men. Models are useful aids in analysis, and it is our aim to introduce to the beginning student the meaning and role of economic models. 